\title{
Obstructive sleep apnoea syndrome in patients with primary open-angle glaucoma
}

\author{
Ege G Balbay *, Oner Balbay, Ali N Annakkaya, Kezban 0 Suner, Harun Yuksel, Murat Tunç, Peri Arbak
}

\section{A B S T R A C T}

Objective: To investigate the prevalence of obstructive sleep apnoea syndrome in patients with primary open-angle glaucoma.

Design: Case series.

Setting: School of Medicine, Düzce University, Turkey.

Patients: Twenty-one consecutive primary open-angle glaucoma patients (12 females and 9 males) who attended the out-patient clinic of the Department of Ophthalmology between July 2007 and February 2008 were included in this study. All patients underwent polysomnographic examination.

Results: The prevalence of obstructive sleep apnoea syndrome was $33.3 \%$ in patients with primary open-angle glaucoma; the severity of the condition was mild in $14.3 \%$ and moderate in $19.0 \%$ of the subjects. The age $(\mathrm{P}=0.047)$ and neck circumference $(\mathrm{P}=0.024)$ in patients with obstructive sleep apnoea syndrome were significantly greater than those without the syndrome. Triceps skinfold thickness in glaucomatous obstructive sleep apnoea syndrome patients reached near significance versus those without the syndrome $(\mathrm{P}=0.078)$. Snoring was observed in all glaucoma cases with obstructive sleep apnoea syndrome. The intra-ocular pressure of patients with primary open-angle glaucoma with obstructive sleep apnoea syndrome was significantly lower than those without obstructive

This article was published on 6 Jun 2014 at www.hkmj.org. sleep apnoea syndrome $(\mathrm{P}=0.006$ and $\mathrm{P}=0.035$ for the right and left eyes, respectively). There was no significant difference in the cup/disc ratio and visual acuity, except visual field defect, between primary open-angle glaucoma patients with and without obstructive sleep apnoea syndrome.

Conclusions: Although it does not provide evidence for a cause-effect relationship, high prevalence of obstructive sleep apnoea syndrome in patients with primary open-angle glaucoma in this study suggests the need to explore the long-term results of coincidence, relationship, and cross-interaction of these two common disorders.

\section{Hong Kong Med J 2014;20:379-85}

DOI: $10.12809 / \mathrm{hkmj} 134021$

\author{
${ }^{1}$ EG Balbay *, MD \\ ${ }^{1} \mathrm{O}$ Balbay, MD \\ ${ }^{1}$ AN Annakkaya, MD \\ ${ }^{1}$ KO Suner, MD \\ ${ }^{2}$ H Yuksel, MD \\ ${ }^{2} \mathrm{M}$ Tunç, MD \\ ${ }^{1} \mathrm{P}$ Arbak, MD
}

${ }^{1}$ Department of Chest Diseases

Department of Ophthalmology

Faculty of Medicine, Düzce University, 81620 Düzce, Turkey

* Corresponding author: egegulecbalbay@gmail.com

This study was presented as thematic poster in the 21st European Respiratory Society Annual Congress in Amsterdam, The Netherlands, 24-28 Sep 2011. The abstract was published in European Respiratory Journal 2011;38(Suppl 55):2253.

New knowledge added by this study

- Although this study did not provide an evidence for a cause-effect relationship between obstructive sleep apnoea syndrome (OSAS) and primary open-angle glaucoma (POAG), the high prevalence of OSAS in patients with POAG might present a new perspective to ophthalmologists when managing glaucoma patients.

Implications for clinical practice or policy

- In clinical practice, OSAS is often not taken into diagnostic consideration for glaucoma patients. The high prevalence of OSAS in patients with POAG might present a new perspective to ophthalmologists and encourage them to explore the long-term results of coincidence, relationship, and cross-interaction of these two common disorders. Based on data from the present study, we recommend eliciting history of sleep apnoea symptoms in patients with glaucoma, especially in those who are obese and have thick necks. We also recommend polysomnography in patients with two or more major sleep disturbance symptoms.

\section{Introduction}

Obstructive sleep apnoea syndrome (OSAS) is characterised by repetitive, complete, or partial collapse of the pharyngeal airway during sleep and, generally, reduction in oxygen desaturation. ${ }^{1}$ The prevalence of OSAS is estimated to be $1 \%$ to $2 \%$ in men and $1.2 \%$ to $2.5 \%$ in women. ${ }^{2}$ The prevalence of OSAS in Turkey was reported as $1.8 \%$ in epidemiological studies. ${ }^{3}$ 


\section{原發性開角型青光眼患者的阻塞性睡眠呼吸 暫停綜合徵}

Ege G Balbay, Oner Balbay, Ali N Annakkaya,

Kezban O Suner, Harun Yuksel, Murat Tunç, Peri Arbak

目的：探討原發性開角型青光眼患者的阻塞性睡眠呼吸暫停綜合徵患 病率。

設計：病例系列。

安排：土耳其迪茲傑大學醫學院。

患者：2007年 7 月至 2008 年 2 月期間於眼科部求診的所有 21 名原發性 開角型青光眼患者 (9男12女) 均納入本研究。所有患者曾接受多導 睡眠圖檢查。

結果：原發性開角型青光眼患者的阻塞性睡眠呼吸暫停綜合徵患病率 為 $33.3 \%$; 其中 $14.3 \%$ 的病情屬輕度, $19.0 \%$ 屬中度。與沒有阻塞性睡 眠呼吸暫停綜合徵的患者比較, 有此症狀的患者年齡 $(\mathrm{P}=0.047)$ 和 頸圍（ $\mathrm{P}=0.024 ）$ 顯著較高, 其三頭肌皮禇厚度較大（ $\mathrm{P}=0.078 ）$, 眼內壓亦顯著較低（右眼： $\mathrm{P}=0.006$; 左眼 : $\mathrm{P}=0.035$ ), 而且所有 具阻塞性睡眠呼吸暫停綜合徵的患者都有打鼾的現象。除視野缺損 外, 兩組患者在杯盤比和視力方面無顯著差異。

結論 : 本研究未能為原發性開角型青光眼和阻塞性睡眠呼吸暫停綜合 徵的因果關係提供證據。然而, 原發性開角型青光眼患者中出現阻塞 性睡眠呼吸暫停綜合徵的高患病率, 顯示須進行遠期觀察來研究這兩 種病症的巧合性、相互關係和交互作用。
Sleep-disordered diseases are associated with a number of eye disorders including floppy eyelid syndrome, optic neuropathy, keratoconus, retinal vascular tortuosity and congestion, retinal bleeding, non-arteritic anterior ischaemic optic neuropathy and papilloedema secondary to increased intracranial pressure, normal tension glaucoma, and primary open-angle glaucoma (POAG) ${ }^{4-7}$ Sleepdisordered breathing may impair autoregulation of optic nerve perfusion due to the direct effect of hypoxia. Glaucoma is a multifactorial and specific optic neuropathy often characterised by increased intra-ocular pressure (IOP) that results in typical and progressive visual field loss. ${ }^{8}$

The prevalence of glaucoma in the general population is between $1 \%$ and $2 \%{ }^{9}$ While the aetiology of POAG still remains unclear, several risk factors have been associated with the condition. It was known that OSAS effects the oxygenation, neurohumoral factors, and vascular haemodynamics. ${ }^{4}$ It has been suggested that OSAS aggravates or even causes glaucoma by impaired optic nerve head blood flow and tissue atrophy, infarction due to vascular dysregulation or by direct damage to the optic nerve secondary to prolonged hypoxia. ${ }^{4,9}$

In addition to elevated IOP, cardiovascular risk factors-such as arterial hypotension and hypertension, vasospasms, autoregulatory defects, and atherosclerosis-are of increasing importance in the pathogenesis of glaucoma, especially in normal-tension glaucoma (NTG). Several recent reports $^{4,5,10,11}$ suggest that OSAS may be an additional risk factor for glaucoma. Some of the possible causes of glaucoma-like abnormal blood coagulation, vasospastic disease, and optic nerve vascular dysregulation are also consequences of OSAS. It is not surprising, therefore, that some studies $^{4,5,10,11}$ show an increased prevalence of OSAS in patients with glaucoma and vice versa. In clinical practice, OSAS is often not taken into diagnostic consideration in glaucoma patients. ${ }^{11}$

The association between glaucoma and OSAS has been reported in many studies. Most of them focused on the prevalence of glaucoma in OSAS patients and indicated it as a risk factor. Some of these articles have been observational case reports or case series., ${ }^{4,12-15}$ The objective of this study was to investigate the prevalence of OSAS in patients with POAG.

\section{Methods}

\section{Study group}

This was a prospective case series that included 30 consecutive adult POAG patients who attended the out-patient clinic of the Düzce University, School of Medicine, Turkey between July 2007 and February 2008. Informed consent was obtained from the study participants.

\section{Exclusion criteria}

Individuals with diabetes mellitus $(n=4)$, thyroid function disorders $(n=2)$, hyperlipidaemia $(n=2)$, and who refused to participate in the study $(n=1)$ were excluded.

\section{Ophthalmological examination}

All patients underwent routine eye examination, including Snellen visual acuity, manifest refraction, slit-lamp examination of the anterior eye segment, IOP measurement, gonioscopy, and binocular examination of the optic disc.

Patients were considered to have POAG if they had untreated IOP of $\geq 21 \mathrm{~mm} \mathrm{Hg}$, an open anterior chamber angle, glaucomatous visual field defects or glaucomatous cupping of the optic disk, and no fundus or neurological lesion other than glaucomatous cupping to account for the visual field defect.

\section{Data collection}

Prior to the sleep test, all POAG patients completed a questionnaire about sleep disturbance. Data 
from the questionnaire were used to evaluate basic OSAS symptoms such as snoring (presence of snoring for at least five nights per week), witnessed apnoea (spouse or relatives of patients with OSAS, identifying noisy and irregular snoring, and arrested respiration through the mouth and nose), and daytime sleepiness. The Epworth Sleepiness Scale was used to objectively evaluate excessive daytime sleepiness. If the score obtained on this scale was above 10, excessive daytime sleepiness was considered present. ${ }^{16}$ All POAG patients received an otorhinolaryngeal examination.

In addition, polysomnography (PSG; SomnoMedics Gmbh-8 Co. KG, Nonnengarten 8, D-97270 Kist Germany. Model: Somnoscreen-PSG, Ser-No: 0372 CAA5-OJ), electroencephalography, electrooculography, chin electromyography, oral and nasal airflow (nasal-oral 'thermistor' and nasal cannula), thorax movements, abdominal movements, arterial oxygen saturation (pulse oximetry instrument), electrocardiogram, and snoring recordings ( $>6$ hours) were obtained from all patients. All records were scored manually in a computer environment. Definitions of various terms are shown in the Box. ${ }^{17}$

\section{Statistical analysis}

Data were analysed using the Statistical Package for the Social Sciences (Windows version 10.0; SPSS Inc, Chicago [IL], US). Mann Whitney $U$ test was used for comparing quantitative data. Chi squared test or Fisher's exact test was used to compare categorical data. A P value of $<0.05$ was considered statistically significant. Spearman's test was used for evaluating correlations between sample pairs.

\section{Results}

Of the 21 POAG patients, 12 were female and 9 were male. Demographic and clinical features of the patients are summarised in Table 1.

BOX. Definitions of various terms used in this study

Apnoea: Complete lack of airflow through the mouth and nose for $\geq 10$ seconds.

Hypopnoea: $50 \%$ Reduction of airflow for $\geq 10$ seconds, along with $3 \%$ decrease in oxygen saturation or leading to arousal.

Apnoea-hypopnoea index: The ratio of the total duration of apnoea and hypopnoea observed during sleep to total length of sleep.

Severity of obstructive sleep apnoea syndrome: When

evaluated based on apnoea-hypopnoea index (AHI):

Normal: $\mathrm{AHI}<5 /$ hour

Mild sleep apnoea: AHI 5-15/hour

Moderate sleep apnoea: AHI 16-30/hour

Severe sleep apnoea: $\mathrm{AHI}>30 /$ hour

Sleep efficiency: Sleep duration/time in bed
Snoring was the most prevalent (81.0\%) major symptom of OSAS; snoring was habitual in $42.9 \%$ of the patients. Daytime sleepiness and witnessed apnoea were found in $23.8 \%$ and $14.3 \%$ of the patients, respectively. While no major symptom was present in $52.4 \%$ of POAG patients, three major symptoms were concomitantly present in one (4.8\%) POAG patient (Table 2).

Polysomnographic study showed that OSAS was present in $33.3 \%(n=7)$ of the POAG patients (apnoea-hypopnoea index [AHI $\geq 5 /$ hour). The severity of OSAS was mild (AHI of 5-15/hour) in $14.3 \%(\mathrm{n}=3)$ and moderate (AHI of 16-30/hour) in $19.0 \%(n=4)$ of the patients. Age $(P=0.047)$ and neck

TABLE I. General characteristics of patients

\begin{tabular}{lc}
\hline Characteristic & $\begin{array}{c}\text { No. (\%) or } \\
\text { mean } \pm \text { SD (range) }\end{array}$ \\
\hline Gender & $12(57.1)$ \\
$\quad$ Female & $9(42.9)$ \\
$\quad$ Male & $56.0 \pm 10.1(38.0-79.0)$ \\
Age (years) & $27.8 \pm 5.5(17.3-40.1)$ \\
Body mass index (kg/m²) & $37.9 \pm 3.4(31.0-44.0)$ \\
Neck diameter (cm) & $14.0 \pm 2.9(10.0-20.0)$ \\
Triceps skinfold thickness (mm) & $41.3 \pm 3.2(33.8-45.9)$ \\
Haematocrit (\%) & $5.2 \pm 6.0(0-20.0)$ \\
OSAS symptom duration (months) & $11(52.4)$ \\
\hline Smoking & \\
\hline
\end{tabular}

Abbreviations: OSAS = obstructive sleep apnoea syndrome; SD = standard deviation

TABLE 2. Frequency of obstructive sleep apnoea syndrome (OSAS) symptoms in patients with primary open-angle glaucoma

\begin{tabular}{|lc|}
\hline OSAS symptom & $\begin{array}{c}\text { No. (\%) of patients } \\
(\mathbf{n = 2 1 )}\end{array}$ \\
\hline Snoring & $17(81.0)$ \\
\hline Snoring severity & $4(19.0)$ \\
\hline No & $12(57.1)$ \\
\hline Mild & $5(23.8)$ \\
\hline Severe & $9(42.9)$ \\
\hline Habitual snoring* & $3(14.3)$ \\
\hline Witnessed apnoea* & $5(23.8)$ \\
\hline Daytime sleepiness* & \\
\hline Major symptoms & $11(52.4)$ \\
\hline No major symptom & $4(19.0)$ \\
\hline 1 Major symptom & $5(23.8)$ \\
\hline 2 Major symptoms & $1(4.8)$ \\
\hline 3 Major symptoms & \\
\hline * Major symptoms & \\
\hline
\end{tabular}


circumference $(P=0.024)$ were significantly higher in POAG patients with OSAS versus those without OSAS; triceps skinfold thickness was also higher in OSAS patients, but it did not reach statistical significance $(\mathrm{P}=0.078)$. No significant difference was observed between POAG patients with and

TABLE 3. The comparison of the features of primary open-angle glaucoma patients with and without obstructive sleep apnoea syndrome (OSAS)

\begin{tabular}{lccc}
\hline Characteristic & \multicolumn{2}{c}{ Mean \pm standard deviation } & P value \\
\cline { 2 - 3 } & With OSAS & Without OSAS & \\
\hline Age (years) & $63.2 \pm 11.5$ & $53.6 \pm 7.8$ & 0.047 \\
Body mass index $\left(\mathrm{kg} / \mathrm{m}^{2}\right)$ & $27.9 \pm 7.4$ & $27.7 \pm 6.6$ & 0.970 \\
Neck circumference $(\mathrm{cm})$ & $40.4 \pm 2.8$ & $36.6 \pm 3.0$ & 0.024 \\
Triceps skinfold thickness $(\mathrm{mm})$ & $15.4 \pm 1.5$ & $13.2 \pm 3.2$ & 0.078 \\
Haematocrit $(\%)$ & $42.7 \pm 2.1$ & $40.6 \pm 3.1$ & 0.117 \\
Symptom duration (years) & $6.7 \pm 7.0$ & $4.5 \pm 5.5$ & 0.473 \\
\hline
\end{tabular}

TABLE 4. The comparison of clinical and ophthalmological features of primary openangle glaucoma patients with and without obstructive sleep apnoea syndrome (OSAS)

\begin{tabular}{|c|c|c|c|}
\hline \multirow{2}{*}{$\begin{array}{l}\text { Clinical and ophthalmological } \\
\text { feature }\end{array}$} & \multicolumn{2}{|c|}{ No. $(\%)$ or mean \pm SD } & \multirow[t]{2}{*}{$P$ value } \\
\hline & With OSAS & Without OSAS & \\
\hline \multicolumn{4}{|l|}{ Gender } \\
\hline Female $(n=12)$ & $2(16.7 \%)$ & $10(83.3 \%)$ & 0.159 \\
\hline Male $(n=9)$ & $5(55.6 \%)$ & $4(44.4 \%)$ & \\
\hline \multicolumn{4}{|l|}{ Smoking } \\
\hline Yes $(n=11)$ & $5(45.5 \%)$ & $6(54.5 \%)$ & 0.361 \\
\hline No $(n=10)$ & $2(20.0 \%)$ & $8(80.0 \%)$ & \\
\hline \multicolumn{4}{|l|}{ Hypertension } \\
\hline Yes $(n=7)$ & $1(14.3 \%)$ & $6(85.7 \%)$ & 0.337 \\
\hline No $(n=14)$ & $6(42.9 \%)$ & $8(57.1 \%)$ & \\
\hline \multicolumn{4}{|l|}{ IOP (mm Hg) } \\
\hline Right $(n=11)$ & $14.0 \pm 2.5$ & $18.5 \pm 3.9$ & 0.006 \\
\hline Left $(n=10)$ & $14.7 \pm 2.6$ & $17.8 \pm 2.8$ & 0.035 \\
\hline \multicolumn{4}{|l|}{ Cup/disc ratio } \\
\hline Right $(n=11)$ & $0.4 \pm 0.2$ & $0.4 \pm 0.2$ & 0.968 \\
\hline Left $(n=10)$ & $0.4 \pm 0.1$ & $0.4 \pm 0.2$ & 0.817 \\
\hline \multicolumn{4}{|l|}{ Visual acuity } \\
\hline Right $(n=7)$ & $0.7 \pm 0.2$ & $0.8 \pm 0.2$ & 0.608 \\
\hline Left $(n=14)$ & $0.7 \pm 0.1$ & $0.9 \pm 0.1$ & 0.223 \\
\hline \multicolumn{4}{|l|}{ Visual field defect } \\
\hline No $(n=14)$ & $5(35.7 \%)$ & 9 (64.3\%) & \\
\hline Unilateral $(n=2)$ & $2(100.0 \%)$ & 0 & 0.038 \\
\hline Bilateral $(n=5)$ & 0 & $5(100.0 \%)$ & \\
\hline $\mathrm{AHI}$ & $13.8 \pm 6.8$ & $2.7 \pm 1.6$ & $<0.001$ \\
\hline Lowest desaturation in PSG (\%) & $81.3 \pm 7.4$ & $85.6 \pm 11.1$ & 0.043 \\
\hline
\end{tabular}

Abbreviations: $\mathrm{AHI}=$ apnoea-hypopnoea index; $\mathrm{IOP}=$ intra-ocular pressure; $\mathrm{PSG}=$ polysomnography; SD = standard deviation without OSAS with regard to body mass index and the duration of one or more major OSAS symptom (Table 3).

Primary open-angle glaucoma patients with and without OSAS did not differ significantly in terms of gender, smoking, hypertension, cup/disc ratio, and visual acuity. Intra-ocular pressure in POAG patients with OSAS was significantly lower than that in patients without OSAS $(\mathrm{P}=0.006$ and $\mathrm{P}=0.035$ for the right and left eyes, respectively). Apnoea-hypopnoea index was significantly higher $(\mathrm{P}<0.001)$ and the lowest desaturation on PSG was significantly lower $(\mathrm{P}=0.043)$ in POAG patients with OSAS than those without OSAS. Visual field defects were significantly more common in POAG patients with OSAS $(\mathrm{P}=0.038)$ [Table 4].

Obstructive sleep apnoea syndrome was not observed in POAG patients with no snoring (including simple snoring). As the degree of snoring increased, OSAS prevalence reached almost statistical significance. The symptoms of habitual snoring $(\mathrm{P}<0.001)$ and witnessed apnoea $(\mathrm{P}=0.026)$ were significantly more frequent in POAG patients with OSAS versus those without OSAS (Table 5).

No correlation was detected between PSG parameters (AHI, lowest desaturation in PSG) and ophthalmologic parameters (cup/disc ratio, visual acuity) in POAG patients (Table 6).

\section{Discussion}

In this study, the prevalence of OSAS and the associated symptoms were higher in POAG patients than that in the general population. ${ }^{2}$ The prevalence of OSAS of at least mild severity was even higher compared with that in middle-aged adults $(9 \%$ in women and $24 \%$ in men). ${ }^{3}$ Intra-ocular pressure levels in patients with OSAS were significantly lower than in those without OSAS. Another important finding of the present study was that there was a statistically significant but clinically insignificant difference between OSAS and non-OSAS patients regarding visual field defect.

Vascular risk factors for POAG have been hypothesised and researched. It has been reported that potential cardiovascular risk factors including systemic hypertension, atherosclerosis, vasospasm, and acute hypotension are associated with glaucoma. ${ }^{5}$ Nevertheless, some patients may experience progression of their neuropathy even though their IOP seems appropriately controlled. Obstructive sleep apnoea syndrome could be considered one of the risk factors for POAG. Since glaucomatous optic neuropathy is multifactorial, treatment of OSAS - which is currently a known and modifiable risk factor-may help the control of IOP and management of glaucoma. ${ }^{18}$

There are a few studies examining the correlation between POAG and OSAS. A recent 
study $^{19}$ determined the prevalence of OSAS in POAG associated with snoring. Thirty-one snoring glaucomatous patients prospectively underwent PSG. Of these, $49 \%$ were diagnosed to have OSAS. ${ }^{19}$ Mojon et $\mathrm{al}^{4}$ performed overnight transcutaneous finger oximetry in 30 consecutive patients having POAG (mean age, $76.0 \pm 7.9$ years) and found that the oximetry disturbance index (ODI) was significantly higher $(11 \%)$ in these patients compared with normal controls of the same age and sex distribution. They reported OSAS prevalence as $20 \%(n=6 / 30)$ in POAG patients according to ODI. ${ }^{4}$ In a group of 16 NTG patients, the OSAS prevalence was $50 \%$ in patients aged 45 to 64 years, and $63 \%$ in patients older than 64 years. ${ }^{10} \mathrm{We}$ found an OSAS prevalence of $33.3 \%$ in POAG patients according to AHI.

Mojon et $\mathrm{al}^{5}$ reported a $7.2 \%$ prevalence of NTG among 69 white patients with OSAS (mean age, $52.6 \pm 9.7$ years), and it was significantly higher than that expected in general white population (2\%). ${ }^{5}$ In another study, Sergi et $\mathrm{al}^{20}$ found a $59 \%$ prevalence of NTG in 51 OSAS patients (mean age, $64 \pm 10$ years). Contrary to the other studies, the prevalence of glaucoma in a study involving 228 patients with OSAS was reported to be the same as in the general population. ${ }^{21}$

Age is a common risk factor of both OSAS and POAG; the latter itself is an ageing-associated disease. The incidence of OSAS in the general population has been shown to be the highest between 45 and 65 years of age. ${ }^{22}$ Thus, high mean age (56.0 years) in our study might have contributed to the observed high prevalence of OSAS.

Snoring is known to be the most common symptom in OSAS. ${ }^{23}$ A group of out-patients, including those with POAG and without POAG, was recruited for evaluation of sleep-disordered breathing symptoms such as snoring, excessive daytime sleepiness, and insomnia with the help of a questionnaire. ${ }^{9}$ The authors reported high prevalence of sleep-disordered breathing in POAG patients. Compared with those without POAG, POAG patients showed a higher prevalence of snoring $(47.6 \%$ vs $38.0 \%)$, snoring plus excessive daytime sleepiness $(27.3 \%$ vs $17.3 \%)$, and snoring plus excessive daytime sleepiness plus insomnia ( $14.6 \%$ vs $7.8 \%) .{ }^{9}$ The authors speculated that the large nocturnal fluctuations in blood pressure of OSAS patients may have interfered with normal ocular haemodynamics, making the eye vulnerable to glaucoma. ${ }^{9}$ In the logistic regression model, snoring was significantly associated with glaucoma. However, that study was not a follow-up study of glaucomatous patients and snoring could not be accepted as a prognostic factor of POAG. ${ }^{9}$ Moreover, their study did not use objective measures such as overnight PSG for the diagnosis; instead, they only relied on self-reported symptoms. ${ }^{9}$ In another study, ${ }^{7}$ the prevalence of
TABLE 5. Frequency of obstructive sleep apnoea syndrome (OSAS) symptoms in patients with primary open-angle glaucoma

\begin{tabular}{|c|c|c|c|}
\hline \multirow[t]{2}{*}{ Symptom } & \multicolumn{2}{|c|}{ No. $(\%)$ of patients } & \multirow[t]{2}{*}{$P$ value } \\
\hline & With OSAS & Without OSAS & \\
\hline \multicolumn{4}{|l|}{ Snoring } \\
\hline Yes $(n=17)$ & 7 (41.2) & $10(58.8)$ & 0.255 \\
\hline No $(n=4)$ & 0 & $4(100.0)$ & \\
\hline \multicolumn{4}{|l|}{ Snoring severity } \\
\hline No $(n=4)$ & 0 & $4(100.0)$ & \\
\hline Mild $(n=12)$ & 4 (33.3) & 8 (66.7) & 0.165 \\
\hline Severe $(n=5)$ & $3(60.0)$ & $2(40.0)$ & \\
\hline \multicolumn{4}{|l|}{ Habitual snoring } \\
\hline Yes $(n=9)$ & 7 (77.8) & $2(22.2)$ & $<0.001$ \\
\hline No $(n=12)$ & 0 & $12(100.0)$ & \\
\hline \multicolumn{4}{|l|}{ Witnessed apnoea } \\
\hline Yes $(n=3)$ & $3(100.0)$ & 0 & 0.026 \\
\hline No $(n=18)$ & 4 (22.2) & $14(77.8)$ & \\
\hline \multicolumn{4}{|l|}{ Daytime sleepiness } \\
\hline Yes $(n=5)$ & $3(60.0)$ & $2(40.0)$ & 0.280 \\
\hline No $(n=16)$ & $4(25.0)$ & $12(75.0)$ & \\
\hline \multicolumn{4}{|l|}{ Major symptoms } \\
\hline No major symptom & 0 & $11(100.0)$ & \\
\hline 1 Major symptom (+) & $2(50.0)$ & $2(50.0)$ & 0.005 \\
\hline 2 Major symptoms (+) & $4(80.0)$ & $1(20.0)$ & \\
\hline 3 Major symptoms (+) & $1(100.0)$ & 0 & \\
\hline \multicolumn{4}{|c|}{ The presence of major symptoms } \\
\hline Yes $(n=10)$ & $7(70.0)$ & $3(30.0)$ & 0.001 \\
\hline No $(n=11)$ & 0 & $11(100.0)$ & \\
\hline
\end{tabular}

TABLE 6. Correlations between polysomnographic parameters and ophthalmologic parameters

\begin{tabular}{|c|c|c|}
\hline & $\begin{array}{c}\text { Apnoea- } \\
\text { hypopnoea index }\end{array}$ & $\begin{array}{c}\text { Lowest } \\
\text { desaturation }\end{array}$ \\
\hline \multicolumn{3}{|c|}{ Visual acuity (right eye) } \\
\hline$P$ value & 0.888 & 0.525 \\
\hline$r$ & -0.033 & 0.147 \\
\hline \multicolumn{3}{|c|}{ Visual acuity (left eye) } \\
\hline$P$ value & 0.199 & 0.101 \\
\hline$r$ & -0.292 & 0.368 \\
\hline \multicolumn{3}{|c|}{ Cup/disk ratio (right eye) } \\
\hline$P$ value & 0.931 & 0.724 \\
\hline$r$ & -0.021 & -0.084 \\
\hline \multicolumn{3}{|c|}{ Cup/disk ratio (left eye) } \\
\hline$P$ value & 0.914 & 0.663 \\
\hline$r$ & 0.025 & -0.101 \\
\hline
\end{tabular}


sleep-disordered breathing symptoms was higher in patients with NTG versus those without NTG (57\% vs $3 \%)$. However, contrary to our study, they only offered PSG to patients with a positive sleep history.? In our study, the prevalence rates of snoring, habitual snoring, witnessed apnoea, excessive daytime sleepiness were $81.0 \%, 42.9 \%, 14.3 \%$, and $23.8 \%$, respectively. The concomitant presence of two or three major OSAS symptoms was observed in $23.8 \%$ and $4.8 \%$ of our POAG patients, respectively. Blumen Ohana et $\mathrm{al}^{19}$ reported high prevalence of OSAS in patients with POAG and suggested that presence of snoring should be explored at interview. Conversely, patients who snore should be asked whether they have POAG, and if so, should undergo all-night sleep recording for the presence of OSAS. ${ }^{19}$ Mojon et $\mathrm{al}^{5}$ also found that respiratory disturbance index (RDI) was positively correlated with IOP in 114 OSAS patients. Because of the observational nature of that study, they concluded only an association between glaucoma and OSAS rather than a direct causal relationship. ${ }^{5}$ A study by Karakucuk et $\mathrm{al}^{15}$ found that the prevalence of glaucoma in patients with OSAS was $12.9 \%(n=4 / 31)$; all these four patients with glaucoma were in the severe OSAS group. There was also a positive correlation between IOP and AHI, and they suggested that increased IOP values may reflect the severity of OSAS. ${ }^{15}$ In another cross-sectional study, there was no correlation between IOP and RDI. ${ }^{21}$ In the present study, IOP level in patients with OSAS was significantly lower than that in those without OSAS. Intra-ocular pressure shows diurnal variation and patients with OSAS may have elevated IOP and perfusional disturbance of retinal nerve fibres during sleep. Therefore, these patients may have completely normal or low IOP during the daytime. On the other hand, most patients with OSAS were regularly under glaucoma medication which lowers the IOP to within normal limits.

Sergi et $\mathrm{al}^{20}$ did not find any difference in the cup/disk ratio between the study patients and the control group. They found a significant correlation between AHI and the cup/disk ratio but none between awake arterial blood gases and the ophthalmologic examination data. ${ }^{20}$ They speculate that POAG could be a consequence of changes in vascular tone and of the increased platelet aggregability which frequently occur in OSAS patients. In contrast with their study, our study shows that the cup/disk ratio did not differ between POAG patients with and without OSAS.

A study in Hong Kong ${ }^{24}$ examined the computerised visual fields and optic discs of OSAS patients with normal IOP and compared these with non-OSAS population. Visual field indices were significantly lower and the incidence of suspicious glaucomatous disc changes was higher versus the control arm. ${ }^{24}$ A variety of visual field defects in OSAS patients were also reported by Mojon et $\mathrm{al}^{25}$ in nine patients; the field defects stabilised in two of these after 18 months following continuous positive airway pressure (CPAP). Kremmer et $\mathrm{al}^{11}$ have also reported patients with NTG and progressive field loss despite IOP-lowering eye drops and surgery. Nevertheless, they stabilised field loss of patients after diagnosis of OSAS and treatment with CPAP. ${ }^{11}$ Although there was statistically significant difference in the visual field defects of POAG patients with and without OSAS in our study, it was clinically insignificant. Only significant glaucomatous visual field defects were considered in our evaluation. Therefore, minor changes due to lenticular opacifications or other aetiology were not taken into account as major glaucomatous visual field changes.

Hypoxaemia and haemodynamic changes resulting from intermittent apnoea and hypopnoea during sleep are believed to play a role in glaucomatous optic neuropathy. ${ }^{21}$ Although there is no clear evidence for a cause-effect relationship in the present study, the high prevalence of OSAS in patients with POAG suggests a possible relationship.

\section{Conclusions}

In this study, the prevalence of OSAS was higher in POAG patients versus the general population. In clinical practice, OSAS is often not taken into diagnostic consideration in glaucoma patients. The high prevalence of OSAS in patients with POAG suggests the need to explore the long-term results of coincidence, relationship, and cross-interaction between these two common disorders. Based on data from the present study, we recommend that the history of sleep apnoea symptoms be asked in patients with glaucoma, especially in those who are obese and have thick necks. In addition, PSG should be performed in those patients with two or more major sleep disturbance symptoms. Further largescale studies are required to explore the long-term results of these two common disorders, particularly in patients who have been treated with CPAP therapy.

\section{References}

1. Sleep-related breathing disorders in adults: recommendations for syndrome definition and measurement techniques in clinical research. The Report of an American Academy of Sleep Medicine Task Force. Sleep 1999;22:667-89.

2. Young T, Palta M, Dempsey J, Skatrud J, Weber S, Badr $\mathrm{S}$. The occurrence of sleep-disordered breathing among middle-aged adults. N Engl J Med 1993;328:1230-5.

3. Köktürk O. Epidemiology of sleep apnea syndrome. Tuberk Toraks 1998;46:193-201.

4. Mojon DS, Hess CW, Goldblum D, Böhnke M, Körner F, Mathis J. Primary open-angle glaucoma is associated with sleep apnea syndrome. Ophthalmologica 2000;214:115-8.

5. Mojon DS, Hess CW, Goldblum D, et al. High prevalence of glaucoma in patients with sleep apnea syndrome. Ophthalmology 1999;106:1009-12. 
6. McNab AA. The eye and sleep apnea. Sleep Med Rev 2007;11:269-76.

7. Marcus DM, Costarides AP, Gokhale P, et al. Sleep disorders: a risk factor for normal-tension glaucoma? J Glaucoma 2001;10:177-83.

8. Dhillon S, Shapiro CM, Flanagan J. Sleep-disordered breathing and effects on ocular health. Can J Ophthalmol 2007;42:238-43.

9. Onen SH, Mouriaux F, Berramdane L, Dascotte JC, Kulik JF, Rouland JF. High prevalence of sleep-disordered breathing in patients with primary open-angle glaucoma. Acta Ophthalmol Scand 2000;78:638-41.

10. Mojon DS, Hess CW, Goldblum D, et al. Normal-tension glaucoma is associated with sleep apnea syndrome. Ophthalmologica 2002;216:180-4.

11. Kremmer S, Selbach JM, Ayertey HD, Steuhl KP. Normal tension glaucoma, sleep apnea syndrome and nasal continuous positive airway pressure therapy-case report with a review of literature [in German]. Klin Monbl Augenheilkd 2001;218:263-8.

12. Grieshaber MC, Flammer J. Blood flow in glaucoma. Curr Opin Ophthalmol 2005;16:79-83.

13. Grieshaber MC, Mozaffarieh M, Flammer J. What is the link between vascular dysregulation and glaucoma? Surv Ophthalmol 2007;52 Suppl 2:S144-54.

14. Hayreh SS. The 1994 Von Sallman Lecture. The optic nerve head circulation in health and disease. Exp Eye Res 1995;61:259-72.

15. Karakucuk S, Goktas S, Aksu M, et al. Ocular blood flow in patients with obstructive sleep apnea syndrome (OSAS). Graefes Arch Clin Exp Ophthalmol 2008;246:129-34.
16. Johns MW. A new method for measuring daytime sleepiness: the Epworth sleepiness scale. Sleep 1991;14:5405 .

17. International classification of sleep disorders, version 2 : diagnostic and coding manual. Rochester, MN: American Academy of Sleep Medicine; 2005.

18. Blumen-Ohana E, Blumen M, Aptel F, Nordmann JP. Glaucoma and sleep apnea syndrome [in French]. J Fr Ophtalmol 2011;34:396-9.

19. Blumen Ohana E, Blumen MB, Bluwol E, Derri M, Chabolle F, Nordmann JP. Primary open angle glaucoma and snoring: prevalence of OSAS. Eur Ann Otorhinolaryngol Head Neck Dis 2010;127:159-64.

20. Sergi M, Salerno DE, Rizzi M, et al. Prevalence of normal tension glaucoma in obstructive sleep apnea syndrome patients. J Glaucoma 2007;16:42-6.

21. Geyer O, Cohen N, Segev E, et al. The prevalence of glaucoma in patients with sleep apnea syndrome: same as in the general population. Am J Ophthalmol 2003;136:10936.

22. Bixler EO, Vgontzas AN, Ten Have T, Tyson K, Kales A. Effects of age on sleep apnea in men: I. Prevalence and severity. Am J Respir Crit Care Med 1998;157:144-8.

23. Köktürk O. The clinical features of OSAS. Tuberk Toraks 1999;47:117-26.

24. Tsang CS, Chong SL, Ho CK, Li MF. Moderate to severe obstructive sleep apnoea patients is associated with a higher incidence of visual field defect. Eye (Lond) 2006;20:38-42.

25. Mojon DS, Mathis J, Zulauf M, Koerner F, Hess CW. Optic neuropathy associated with sleep apnea syndrome. Ophthalmology 1998;105:874-7. 